\title{
STRUKTUR VEGETASI HUTAN MANGROVE DAN PEMANFAATANNYA DI KAMPUNG ABABIAIDI DISTRIK SUPIORI SELATAN KABUPATEN SUPIORI
}

\author{
Maklon Warpur \\ Jurusan Biologi FMIPA, Universitas Cenderawasih \\ email:womniswarpur@yahoo.com
}

Diterima : 28 Mei 2016 Ditinjau :10 Oktober 2016 Disetujui : 04 November 2016

\begin{abstract}
Abstrak. Ekosistem hutan mangrove merupakan suatu vegetasi yang tumbuh di lingkungan estuaria pantai yang dapat ditemukan pada garis pantai tropika dan subtropika yang memiliki fungsi secara ekologi, biologi, ekonomi dan sosial budaya, namun saat ini keberadaannya telah mengalami degradasi akibat pemanfaatan yang kurang tepat, dan/atau mengalami perubahan fungsi. Penelitian tentang struktur vegetasi hutan mangrove di kampong Ababiaidi Distrik Supiori Selatan Kabupaten Supiori dilakukan pada bulan November 2015 dengan tujuan untuk mengetahui struktur vegetasi hutan mangrove dan pemanfaatannya. Metode yang digunakan dalam penelitian ini adalah pendekatan ekologi/biologi dan pendekatan antropologi. Dari hasil analisis vegetasi, ditemukan sebanyak 12 jenis tumbuhan mangrove. Rhizophora apiculata merupakan jenis yang dominan pada tingkat pohon dengan nilai kerapatan 809,34 individu/Ha dengan indeks nilai penting (INP) 51,98 kemudian diikuti Rhizophora stylosa dengan nilai kerapatan 721,67 individu/Ha dengan dengan indeks nilai penting (INP) 44,01. Pada tingkat belta Rhizophora stylosa merupakan jenis yang dominan dengan nilai kerapatan 488,33 individu/Ha dengan dengan indeks nilai penting (INP) 63,26 kemudian Rhizophora apiculata dengan nilai kerapatan 416,67 individu/ Ha dengan dengan indeks nilai penting (INP) 49,32. Pada tingkat semai Rhizophora stylosa merupakan jenis dominan dengan nilai kerapatan 916,67 individu/Ha dengan dengan indeks nilai penting (INP) 33,07 dan Rhizophora apiculata dengan nilai kerapatan 800 individu/Ha dengan dengan indeks nilai penting (INP) 29,47. Berdasarkan hasil wawancara dari 12 jenis tumbuhan mangrove yang ditemukan dalam plot pengamatan 9 jenis dimanfaatkan sebagai bahan bangunan, 11 sebagai sumber kayu bakar, 3 jenis sebagai obat-obatan dan 4 jenis untuk keperluan lainnya.
\end{abstract}

Kata kunci: Hutan mangrove, kampung Ababiaidi

\begin{abstract}
Mangrove forest is a vegetation that grows in the estuary beaches can be found on the shoreline tropical and subtropical who has the function of ecological, biological, economic and social culture, but now its existence has been degraded by the use of a less appropriate, and / or changing function. Research on the structure of mangrove forest vegetation in the village Ababiaidi Supiori District of Southern District Supiori conducted in November 2015 with the aim to determine the structure of mangrove forest vegetation and utilization. The method used in this research is the approach of ecological / biological and anthropological approach. From the analysis of vegetation, found as many as 12 species of mangrove plants. Rhizophora apiculata is the dominant species on the level of a tree with a density value of 809.34 individuals / ha with an important value index (IVI) 51.98 followed Rhizophora stylosa with a density value of 721.67 individuals / ha with the important value index (IVI) 44 01. At the level of Rhizophora belta stylosa is the dominant species with a density value of 488.33 individuals / ha with the important value index (IVI) 63.26 then Rhizophora apiculata with a density value of 416.67 individuals / ha with the important value index (IVI) 49 , 32. At the seedling stage Rhizophora stylosa a dominant species with a density value of 916.67 individuals / ha with the important value index (IVI) 33.07 and Rhizophora apiculata had density of 800 individuals / ha with the important value index (IVI) 29.47. Based on interviews of 12 mangrove species found in the observation plot 9 species used as building material, 11 species as a source of firewood, 3 species as drugs and 4 species for other purposes.
\end{abstract}


Keywords: mangrove forests, Ababiaidi villages.

\section{PENDAHULUAN}

Indonesia sebagai daerah tropis mempunyai keanekaragaman hayati tinggi, baik di darat maupun di laut khususnya di wilayah pesisir. Tingginya keanekaragaman hayati tersebut tidak lepas dari kondisi geofisik dan letak geografis perairan Indonesia (Begen, 2002 ; Supriharyono 2002, ; Kaswadji, 2001 ; Dahuri, et al., 2004 ; Frieldidan Zulkifli, 2012). Salah satu unsur keanekaragaman hayati wilayah pesisir dan laut adalah ekosistem hutan mangrove. Hutan mangrove sebagai suatu kelompok tumbuhan yang terdiri atas berbagai macam jenis dari suku yang berbeda, namun memiliki daya adaptasi, morfologi dan fisiologi yang sama terhadap habitat yang selalu dipengaruhi oleh pasang surut air laut (Kordi, 2012 ; Saparinto, 2007 ; Eduard dan Husain, 2014).

Ditinjau dari fungsi ekologi, sumber daya mangrove mempunyai beberapa fungsi dilihat dari beberapa aspek antara lain aspek fisik, kimia maupun biologi. Fungsi ini sangat menunjang pemenuhan kebutuhan hidup manusia dan berfungsi sebagai penyangga keseimbangan ekosistem di wilayah pesisir. Fungsi ekologi ditinjau dari aspek fisik antara lain mampu berperan sebagai penahan abrasi, penahan angin/badai, penahan banjir, sebagai kawasan penyangga proses intrusi atau rembesan air laut ke darat atau sebagai filter air asin menjadi tawar. Dari aspek kimia: hutan mangrove dapat berfungsi sebagai penyerap bahan pencemar, khususnya bahanbahan organik sebagai sumber energi bagi lingkungan perairan sekitarnya, pensuplai bahan-bahan organik bagi lingkungan perairan, sebagai tempat terjadinya proses daur ulang yang menghasilkan oksigen dan menyerap karbondioksida, sebagai tempat pengolah bahan-bahan limbah industri. Fungsi Biologi antara lain sebagai penghasil bahan pelapukan yang merupakan sumber makanan penting bagi invertebrata kecil pemakan bahan pelapukan kemudian berperan sebagai sumber makanan bagi hewan yang lebih besar. Selain itu hutan mangrove juga sangat bermanfaat sebagai kawasan pemijah atau asuhan bagi biota laut yang setelah dewasa akan kembali ke laut, sebagai tempat berlindung, bersarang serta berkembang biak bagi burung dan satwa lain, sebagai habitat alami bagi berbagai jenis biota darat maupun biota laut lainnya (Saparinto, 2007; Arief, 2007; Nontji, 2002).

Bila dilihat dari aspek sosial ekonominya, hutan mangrove memiliki manfaat yang relatif besar bagi masyarakat, khususnya masyarakat yang tinggal di sekitarnya antara lain: hutan mangrove bermanfaat sebagai penyedia keperluan rumah tangga; misalnya sebagai bahan bangunan, kayu bakar dan arang; sebagai area pertambakan. Selain itu mangrove juga berperan dalam keperluan industri; misalnya sebagai bahan baku kertas, bahan baku penyamak kulit dan juga sebagai bahan baku kayu lapis (Satari, Cholik dan Naamin 1996; Noor et al ,2006). Walaupun hutan mangrove memiliki fungsi ekologi dan manfaat sosial ekonomi yang sangat penting, namun saat ini keberadaannya telah mengalami degradasi akibat pemanfaatan yang kurang tepat, dan atau mengalami perubahan fungsi. Oleh karena itu perlu dilakukan penelitian untuk mengetahui keanekaragaman hayati hutan mangrove sebelum mengalami penururunan jenis akibat terjadinya degradasi.

\section{BAHAN DAN METODE}

Metode yang digunakan dalam penelitian ini adalah dengan menggunakan 2 (dua) pendekatan, yiatu Ekologi / Biologi dan pendekatan Antropologi. Untuk mengetahui kondisi vegetasi hutan mangrove dilakukan dengan pendekatan ekologi yaitu dengan Metode Transek Kuadrat, sedangkan penetuan plot pengamatan dilakukan secara random.

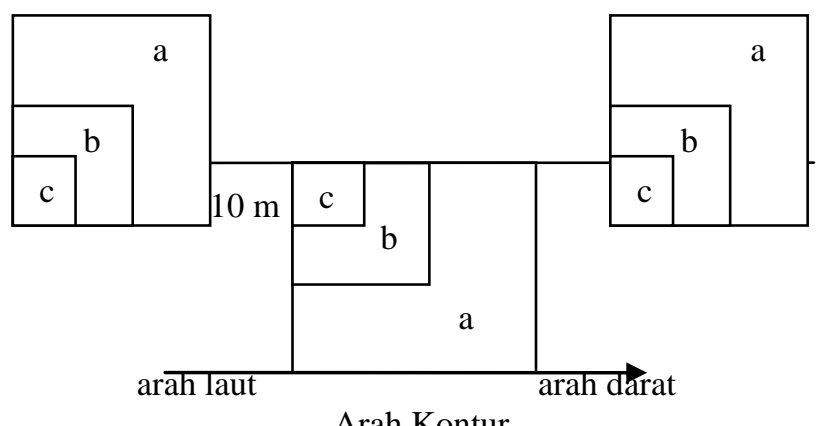

Arah Kontur 
Keterangan:

Petak Sub-plot a, ukuran $10 \times 10 \mathrm{~m}$ untuk tingkat pohon

Petak Sub-plot b, ukuran 5 x 5 m untuk tingkat belta/anakan pohon

Petak Sub-plot c, ukuran 1 x 1 m untuk tingkat semai

Pendekatan antropologis digunakan untuk menggambarkan bagaimana manfaat ekologis, sosial ekonomi dan budaya hutan mangrove di kampung Ababiaidi melalui wawancara. Analisis data dilakukan secara deskripsi kualitatif untuk mengetahui pemanfaatan keanekaragaman hayati hutan mangrove serta deskriptif kuantitatif digunakan untuk mengetahui struktur vegetasi hutan mangrove sebagai berikut (Fachrul, 2007):

Kerapatan $=\frac{\text { jumlah total individu suatu jenis }}{\text { luas total area }}$

Kerapatan Relatif $(\mathrm{KR})=$

$=\frac{\text { Kerapatan suatu jenis }}{\text { kerapatan individu seluruh jenis }} \times 100 \%$

Dominansi $=\frac{\text { luas basal }}{\text { luas petak contoh }}$

Dominansi Relatif $=\frac{\text { Domin ansi suatu jenis }}{\text { Dominansi seluruh jenis }} \times 100 \%$

Frekuensi $=\frac{\text { Jumlah petak sampel tempat ditemukan suatu jenis }}{\text { Jumlah total petak sampel yang diamati }}$

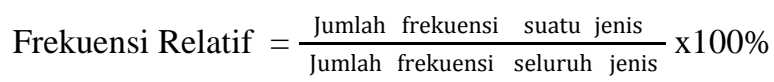

Indeks Nilai Penting $(\mathrm{INP})=\mathrm{KR}+\mathrm{DR}+\mathrm{FR}$

Sedangkan untuk mengetahui tingkat keanekaragaman jenis jenis $\left(\mathrm{H}^{\prime}\right)$, digunakan rumus indeks keanekaragaman berdasarlan Shannon-Wienner (1949) dalam Krebs (1989).
$\mathrm{N}$

$\mathrm{H}^{\prime}=-\sum \mathrm{ni} / \mathrm{Nl} \log \mathrm{ni} / \mathrm{N}$

Dimana :

$\mathrm{H}^{\prime}$ = Indeks Keanekaragaman Shannon-Wienner

$\mathrm{ni}=$ Jumlah individu dari suatu jenis $\mathrm{i}, \mathrm{i}=1,2,3, \ldots$

$\mathrm{N}=$ Jumlah total individu seluruh jenis

\section{HASIL}

\section{Kondisi Hutan Mangrove}

Berdasarkan hasil analisis vegetasi yang telah dilakukan ditemukan sebanyak 12 jenis tumbuhan mangrove dari 5 familia (Tabel 1).

Tabel 1. Keragaman Jenis Mangrove di Kampung Ababiaidi

\begin{tabular}{|c|c|c|}
\hline No & Familia & Jenis \\
\hline 1 & Rhizophoraceae & $\begin{array}{l}\text { Rhizophora apiculata } \\
\text { Rhizophora stylosa } \\
\text { Bruguiera gymnorrhiza } \\
\text { Bruguiera sexangula } \\
\text { Bruguiera cylindrica }\end{array}$ \\
\hline 2 & Soneratiaceae & $\begin{array}{l}\text { Sonneratia alba } \\
\text { Sonneratia caestonopsis }\end{array}$ \\
\hline 3 & Meliacea & Xilocarpus granatum \\
\hline 4 & Malvaceae & $\begin{array}{l}\text { Hibiscus tiliaceus } \\
\text { Thespesia populnae }\end{array}$ \\
\hline 5 & Lecidaceae & Baringtonia asiatica \\
\hline 6 & Combretacea & Terminalia catapa \\
\hline
\end{tabular}

Dari 12 jenis tumbuhan mangrove tersebut, jenis Rhizophora apiculata, Rhizophora stylosa dan Bruguiera gymnorrhiza merupakan jenis yang dominan pada vegetasi tingkat pohon, pancang maupun semai (Tabel 2, 3 dan 4).

Tabel 2. Nilai Kerapatan Relatif, Frekwensi Relatif, Dominansi Relatif, INP dan H'Tingkat Pohon pada Kampung Ababiaidi

\begin{tabular}{|c|c|c|c|c|c|c|c|c|c|}
\hline No & Nama jenis & $\mathrm{K}$ & KR & $\mathrm{F}$ & FR & $\mathrm{D}$ & DR & INP & $\mathrm{H}$ \\
\hline 1 & Rhizophora apiculata & 809,34 & 17,69 & 0,52 & 14,62 & 20287,54 & 20,57 & 51,98 & 0,31 \\
\hline 2 & Rhizophora stylosa & 721,67 & 15,66 & 0,48 & 13,68 & 15128,52 & 15,34 & 44,01 & 0,28 \\
\hline 3 & Bruguiera gymnorrhiza & 633,33 & 13,84 & 0,50 & 14,15 & 12446,18 & 12,62 & 40,06 & 0,27 \\
\hline 4 & Bruguiera sexangula & 450,00 & 9,83 & 0,43 & 12,26 & 11234,14 & 11,39 & 32,99 & 0,24 \\
\hline 5 & Bruguiera cylindrica & 566,67 & 12,38 & 0,47 & 13,21 & 11303,22 & 11,46 & 36,55 & 0,26 \\
\hline 6 & Sonneratia alba & 483,33 & 10,56 & 0,45 & 12,74 & 8907,40 & 9,03 & 31,94 & 0,24 \\
\hline 7 & Sonneratia caseolaris & 516,67 & 11,29 & 0,43 & 12,26 & 11359,74 & 11,52 & 43,57 & 0,25 \\
\hline 8 & Xilocarpus granatum & 183,33 & 4,01 & 0,12 & 3,30 & 4326,92 & 4,39 & 11,50 & 0,13 \\
\hline 9 & Thespesia populnae & 116,67 & 2,55 & 0,08 & 2,36 & 1656,35 & 1,68 & 6,51 & 0,08 \\
\hline 10 & Hibiscus tiliaceus & 33,33 & 0,73 & 0,02 & 0,47 & 573,05 & 0,58 & 1,78 & 0,03 \\
\hline 11 & Thespesia populnae & 33,33 & 0,73 & 0,02 & 0,47 & 487,49 & 0,49 & 1,60 & 0,03 \\
\hline
\end{tabular}




\begin{tabular}{|c|c|c|c|c|c|c|c|c|c|}
\hline 12 & Terminalia catapa & 33,33 & 0,73 & 0,02 & 0,47 & 918,45 & 0,93 & 2,13 & 0,04 \\
\hline & Jumlah & 4576,01 & 100,00 & 3,53 & 100,00 & 103129,38 & 100,00 & 300,00 & 2,19 \\
\hline
\end{tabular}

Tabel 3. Kerapatan Relatif, Frekwensi Relatif, Dominansi Relatif, INP dan H' Tingkat Belta pada Kampung Ababiaidi

\begin{tabular}{lllllllllc}
\hline No & Nama jenis & K & KR & F & FR & D & DR & INP & H' \\
\hline 1 & Rhizophora stylosa & 483,33 & 18,71 & 0,30 & 17,82 & 702,58 & 26,73 & 63,26 & 0,33 \\
2 & Rhizophora apiculata & 416,67 & 16,13 & 0,27 & 15,84 & 456,09 & 17,35 & 49,32 & 0,30 \\
3 & Bruguiera gymnorrhiza & 383,33 & 14,84 & 0,25 & 14,85 & 359,53 & 13,68 & 43,37 & 0,28 \\
4 & Bruguiera sexangula & 350,00 & 13,55 & 0,25 & 14,85 & 222,94 & 8,48 & 36,88 & 0,26 \\
5 & Bruguiera cylindrica & 316,67 & 12,26 & 0,17 & 9,90 & 216,66 & 8,24 & 30,40 & 0,23 \\
6 & Sonneratia alba & 266,67 & 10,32 & 0,18 & 10,89 & 196,25 & 7,47 & 28,68 & 0,22 \\
7 & Sonneratia caseolaris & 216,67 & 8,39 & 0,15 & 8,91 & 233,93 & 8,90 & 26,20 & 0,21 \\
8 & Xilocarpus granatum & 66,67 & 2,58 & 0,05 & 2,97 & 67,51 & 2,57 & 8,12 & 0,10 \\
9 & Hibiscus tiliaceus & 33,33 & 1,29 & 0,02 & 0,99 & 69,87 & 2,66 & 4,94 & 0,07 \\
10 & Baringtonia asiatica & 16,67 & 0,65 & 0,02 & 0,99 & 50,24 & 1,91 & 3,55 & 0,05 \\
11 & Terminalia catapa & 16,67 & 0,65 & 0,02 & 0,99 & 28,26 & 1,08 & 2,71 & 0,04 \\
12 & Thespesia populnae & 16,67 & 0,65 & 0,02 & 0,99 & 24,53 & 0,93 & 2,57 & 0,04 \\
& Jumlah & 2583,34 & 100,00 & 1,68 & 100,00 & 2628,38 & 100,00 & 300,00 & 2,13 \\
\hline
\end{tabular}

Tabel 4.Nilai Kerapatan Relatif, Frekwensi Relatif, , INP dan H’ Tingkat Semai pada Kampung Ababiaidi

\begin{tabular}{|c|c|c|c|c|c|c|c|}
\hline No & Nama jenis & $\mathrm{K}$ & KR & $\mathrm{F}$ & FR & INP & $\mathrm{H}$ \\
\hline$\overline{1}$ & Rhizophora stylosa & 916,67 & 15,58 & 0,53 & 17,49 & 33,07 & 0,30 \\
\hline 2 & Rhizophora apiculata & 800,00 & 13,60 & 0,48 & 15,85 & 29,44 & 0,28 \\
\hline 3 & Bruguiera gymnorrhiza & 716,67 & 12,18 & 0,43 & 14,21 & 26,39 & 0,27 \\
\hline 4 & Bruguiera sexangula & 783,33 & 13,31 & 0,48 & 15,85 & 29,16 & 0,28 \\
\hline 5 & Bruguiera cylindrica & 633,33 & 10,76 & 0,42 & 13,66 & 24,43 & 0,26 \\
\hline 6 & Sonneratia alba & 483,33 & 8,22 & 0,25 & 8,20 & 16,41 & 0,21 \\
\hline 7 & Sonneratia caseolaris & 533,33 & 9,07 & 0,13 & 4,37 & 13,44 & 0,18 \\
\hline 8 & Xilocarpus granatum & 316,67 & 5,38 & 0,10 & 3,28 & 8,66 & 0,14 \\
\hline 9 & Hibiscus tiliaceus & 250,00 & 4,25 & 0,08 & 2,73 & 6,98 & 0,12 \\
\hline 10 & Thespesia populnae & 216,67 & 3,68 & 0,08 & 2,73 & 6,41 & 0,11 \\
\hline 11 & Baringtonia asiatica & 116,67 & 1,98 & 0,02 & 0,55 & 2,53 & 0,06 \\
\hline \multirow[t]{2}{*}{12} & Terminalia catapa & 116,67 & 1,98 & 0,03 & 1,09 & 3,08 & 0,06 \\
\hline & Jumlah & 5883,34 & 100,00 & 3,05 & 100,00 & 200,00 & 2,25 \\
\hline
\end{tabular}

\section{Pemanfaatan Hutan Mangrove oleh Masyarakat Ababiaidi}

Menurut hasil wawancara dengan responden diketahui bahwa aneka ragam hayati hutan mangrove dimanfaatkan penduduk untuk berbagai kegunaan seperti pemanfaatan tumbuhan mangrove sebagai bahan bangunan, sumber kayu bakar, sumber bahan obat dan keperluan lainnya seperti sumber bahan pangan, pewarna dan alat tarnsportasi.
a. Pemanfaatan Tumbuhan Mangrove sebagai Sumber Bahan Bangunan 
Tabel 5. Jenis Mangrove yang Dimanfaatkan sebagai Bahan Bangunan

\begin{tabular}{llll}
\hline No & Jenis & Nama Lokal & Kegunaan \\
\hline 1 & Rhizophora apiculata & Ampiuw (bon mgun) & Tiang penyangga \\
2 & Rhizophora stylosa & Ampiuw (bon beba) & Tiang penyangga \\
3 & Bruguiera gymnorrhissa & Aibon & Tiang penyangga \\
4 & Bruguiera sexangula & Aibon & Tiang penyangga \\
5 & Bruguiera cylindrica & Aibon & Tiang penyangga \\
6 & Sonneratia alba & Swai/sawawir (bon beba) & Tiang penyangga \\
7 & Sonneratia caseolaris & Swai/sawawir (bon mgun) & Tiang penyangga \\
8 & Xylocarpus granatum & Kabau & Tiang penyangga \\
9 & Terminalia catappa & Kris & Pengalas lantai \\
\hline
\end{tabular}

Sumber Data: Data Primer (2010)

b. Pemanfaatan Tumbuhan Mangrove sebagai Sumber Bahan Kayu Bakar

Terdapat 12 jenis tumbuhan mangrove

yang digunakan sebagai sumber kayu bakar oleh sebagian besar anggota masyarakat Kampung Ababiaidi (Tabel 6).

Tabel 6. Jenis Mangrove yang Dimanfaatkan sebagai Kayu Bakar

\begin{tabular}{llll}
\hline No & Jenis & Nama Lokal & Bagian yang digunakan \\
\hline 1 & Rhizophora apiculata & Ampiuw (bon mgun) & Ranting, batang pohon \\
2 & Rhizophora stylosa & Ampiuw (bon beba) & Ranting, batang pohon \\
3 & Bruguiera gymnorrhissa & Aibon & Ranting, batang pohon \\
4 & Bruguiera sexangula & Aibon & Ranting, batang pohon \\
5 & Bruguiera cylindrica & Aibon & Ranting, batang pohon \\
6 & Ceriops tagal & Manggringgring & Ranting, batang pohon \\
7 & Sonneratia alba & Swai/sawawir & Ranting, batang pohon \\
8 & Sonneratia caseolaris & Swai/sawawir & Ranting, batang pohon \\
9 & Xylocarpus granatum & Kabau & Ranting, batang pohon \\
10 & Terminalia catappa & Kris & Ranting, batang pohon \\
11 & Hibiscus tiliaceus & Amfan & Ranting, batang pohon \\
\hline
\end{tabular}

c. Pemanfaatan Tumbuhan Mangrove sebagai Sumber Bahan Obat

Hasil identifikasi tumbuhan mangrove yang dimanfaatkan oleh masyarakat Ababiaidi sebagai obat tradisional dijumpai dalam plot pengamatan sebanyak 2 jenis (Tabel.7).

\section{d. Pemanfaatan Tumbuhan Mangrove sebagai Sumber Bahan Keperluan Lainnya}

Hasil identifikasi tumbuhan mangrove yang dimanfaatkan oleh masyarakat Ababiaidi
Tabel 7. Jenis Mengrove yang Dimanfaatkan sebagai Obat

\begin{tabular}{rll}
\hline No & Jenis & Nama Lokal \\
\hline 1 & Sonneratia alba & Swai \\
2 & Sonneratia & Swai \\
3 & $\begin{array}{l}\text { caseolaris } \\
\text { Terminalia catappa }\end{array}$ & Kris \\
\hline
\end{tabular}

keperluan lainnya seperti pangan, bahan pewarna, dan alat tarnsportasi seperti perahu dijumpai sebanyak 3 jenis (Tabel 8 ).

Tabel 8. Jenis Mengrove yang Dimanfaatkan sebagai Sumber Bahan Keperluan Lainnya

\begin{tabular}{llll}
\hline No & Jenis & Nama Lokal & Kegunaan \\
\hline 1 & Bruguiera gymnorrhissa & Aibon & Pangan \\
2 & Rhizophora sp. & ampiuw & Pewarna \\
3 & Terminalia catappa & Kris & Perahu \\
4 & Baringtonia asiatica & Rabon & Racun Ikan \\
\hline
\end{tabular}

PEMBAHASAN

Kondisi Vegetasi Hutan Mangrove
Hasil analisis data melalui nilai kerapatan maupun penyebaran jenis tumbuhan mangrove yang telah dilakukan menunjukkan bahwa Rhizophora merupakan jenis yang 
dominan dalam vegetasi hutan mangrove pada lokasi penelitian baik pada vegetasi tingkat pohon, belta dan semai. Hal ini diperkuat oleh pendapat Kustanti (2011), bahwa Rhizophora merupakan salah satu jenis tumbuhan mangrove yang dominan dalam suatu kawasan hutan mangrove.

Melalui analisis nilai kerapatan menunjukkan bahwa vegetasi mangrove pada lokasi studi belum mendapatkan gangguan yang berarti dari masyarakat setempat, walaupun pada beberapa tempat telah mengalami gangguan berupa pembukaan hutan mangrove sebagai lokasi pemukiman tetapi masih dalam sakala yang kecil. Menurut Fachrul (2007) kerapatan dapat digunakan untuk melihat besarnya gangguan terhadap suatu habitat. jika nilai kerapatan jenis tumbuhan pada suatu habitat rendah/kecil maka pada habitat tersebut telah mengalami kerusakan, sebaliknya jika nilai kerapatan jenis tumbuhan tersebut besar/tinggi maka pada habitat tersebut belum mengalami kerusakan.

Berdasarkan hasil analsis yang telah dilakukan, nilai kerapatan pada lokasi pengamatan berkisar antara 33,33-809,34/ha. Nilai tersebut jika dibandingkan dengan Nilai Kriteria Baku Kerusakan Mangrove berdasarkan Kepmeneg LH No.201 Tahun 2004, maka dapat dikatakan bahwa kondisi vegetasi hutan mangrove di Supiori terutama pada lokasi penelitian dikategorikan sebagai rusak dan jarang karena berada di bawah nilai 1000. Hasil ini diperkuat dengan data dari BPDAS Mamberamo (2007) bahwa 1369 ha kawasan hutan mangrove di kabupaten Supiori mengalami rusak berat, 1236 ha dalam keadaan rusak, dan sisanya 431 ha dalam kondisi baik. Berikut Kriteria Baku Kerusakan Mangrove berdasarkan Kepmeneg LH No.201 Tahun 2004.

Tabel 9. Kriteria Baku Kerusakan Mangrove

\begin{tabular}{ccc}
\hline \multicolumn{2}{c}{ Kriteria } & $\begin{array}{c}\text { Kerapatan } \\
\text { (Pohon/ha) }\end{array}$ \\
\hline Baik & $\begin{array}{l}\text { Sangat } \\
\text { Padat }\end{array}$ & $>1500$ \\
& Sedang & $>1000-1500$ \\
Rusak & Jarang & $<1000$ \\
\hline
\end{tabular}

Sumber: Kepmeneg LH No.201 Tahun 2004

Jika dilihat dari penyebaran dan keragaman jenis, maka jenis Rhizophora merupakan jenis yang memiliki penyebaran yang merata, hal ini dikarenakan subsrat pada lokasi berupa pasir berkarang dan berlumpur mulai dari garis pantai sampai ke arah daratan menyebabkan jenis-jenis yang tumbuh lebih beragam. Sementara itu perhitungan nilai keanekaragaman jenis $\left(\mathrm{H}^{\prime}\right)$ di lokasi penelitian menunjukkan bahwa sebaran individu dan keanekaragaman jenis pada daerah tersebut tergolong sedang karena menurut klasifikasi Odum (1971) nilai ideks keanekaragaman antara 1 - 3 memiliki nilai keanekaragaman sedang dan indeks keanekaragaman lebih dari tiga merupakan keanekaragaman yang tinggi. Berdasarkan analisis data di atas, maka dapat dikatakan bahwa ekosistem mangrove di wilayah ini sudah mulai mendapat tekanan ekologis, karena secara umum keanekaragaman yang tinggi menunjukkan keseimbangan ekosistem yang lebih baik dan memberikan ketahanan yang lebih besar terhadap gangguan, perubahan faktor lingkungan dan lain sebagainya, sedangkan pada daerah tersebut keanekaragamannya tergolong sedang.

\section{Pemanfaatan Hutan Mangrove oleh Masyarakat Ababiaidi}

Menurut hasil wawancara dengan responden diketahui bahwa aneka ragam hayati hutan mangrove dimanfaatkan penduduk untuk berbagai kegunaan seperti pemanfaatan tumbuhan mangrove sebagai bahan bangunan, sumber kayu bakar, sumber bahan obat, dan manfaat lainnya seperti sumber bahan pangan dan pewarna, alat transportasi dan racun

\section{a. Pemanfaatan Tumbuhan Mangrove sebagai Sumber Bahan bangunan}

Bagi masyarakat yang mendiami wilayah pesisir terutama di sekitar hutan mangrove, hutan mangrove merupakan sumber bahan bangunan bagi mereka. Pemanfaatan kayu sebagai bahan bangunan diperoleh dari hutan mangrove di sekitarnya terutama sebagai tiang penyangga bangunan perumahan, jembatan dan tempat penambatan perahu dan hanya diperlukan pada saat mendirikan serta memperbaiki rumah terutama di Kampung Rayori. Dengan demikian kebutuhan kayu untuk bahan bangunan rumah, jembatan 
maupun tempat penambatan perahu diambil dari hutan terdekat terutama hutan mangrove di sekitar kampung. Untuk keperluan tiang penopang bangunan mereka memanfaatkan kayu dari hutan mangrove, seperti swai (Sonneratia $\mathrm{sp}$ ) aibon (Bruguiera $\mathrm{sp}$ ) ampiuw (Rhizophora sp), manggringgring (Ceriops tagal). Jenis-jenis ini dianggap memiliki sifat kuat dan tahan air, sedangkan jenis durnur (Heritiera littoralis) dan Kabau (Xylocarpus granatum) dimanfaatkan untuk papan bangunan ruma dan sebagai atapnya biasanya digunakan daun sanenem (Nypa fruticans). Pemanfaatan pohon mangrove sebagai bahan bangunan oleh masyarakat dilakukan secara selektif dimana pengambilannya dilakukan hanya pada saat mendirikan atau pun memperbaiki rumah dan jembatan sehingga tidak mengancam keberadaan jenis-jenis tersebut.

\section{b. Pemanfaatan Tumbuhan Mangrove sebagai Sumber Bahan Kayu Bakar}

Sebagian besar anggota masyarakat menggunakan kayu pohon mangrove sebagai sumber energi untuk kebutuhan memasak diperoleh dengan mudah dari hutan mangrove di sekitarnya. Pemanfaatan jenis-jenis pohon mangrove sebagai bahan kayu bakar didasarkan atas pengetahuan mereka tentang jenis-jenis tersebut. Berdasarkan pengalaman berinterkasi dengan hutan mangrove secara turun temurun, mereka mengetahui jenis mana yang baik untuk dijadikan sebagai bahan kayu bakar. Hampir semua jenis pohon mangrove dapat dimanfaatkan sebagai kayu bakar, namun menurut pengetahuan masyarakat bahwa jenis aibon (Bruguiera sp), ampiuw (Rhizophora $\mathrm{sp}$ ), dan Xeriops tagal memiliki bentuk pohon yang lurus dan kuat serta walaupun dalam keadaan basah dapat menghasilkan bara api sehingga memiliki kualitas kayu yang baik untuk dijadikan sebagai kayu bakar.

Proses pengambilan kayu bakar adalah dengan mengumpulkan ranting dan batang kayu mangrove yang telah tumbang atau menebang langsung pohon kayu, kemudian dipotong sesuai dengan ukuran yang diinginkan. Volume pengambilan kayu bakar tergantung dari besar kecilnya jumlah anggota keluarga dalam satu rumah tangga, karena semakin banyak anggota keluarga maka semakin banyak pula pohon mangrove yang dibutuhkan sebagai kayu bakar.

\section{c. Pemanfaatan Tumbuhan Mangrove sebagai Sumber Bahan Obat}

Pengolahan tumbuhan mangrove sebagai obat oleh masyarakat Ababiaidi adalah direbus, kemudian air rebusannya diminum untuk menyembuhkan penyakit yang sedang dialami. Beberapa tumbuhan mangrove yang dimanfaatkan untuk obat antara lain: swai (Sonneratia sp) air rebusan kulit pohonya dipakai kumur sebagai obat sakit gigi. Ada beberapa jenis tumbuhan mangrove lainnya yang walaupun tidak ditemukan dalam plot pengamatan, tetapi berdasarkan hasil wawancara dapat dimanfaatkan sebagai obat tardisional antara lain: Parem (Scyphiphora hydrophyllacea) pucuk daun mudah dimakan sebagai obat KB, kabisasu (Acanthus illicifolius) air rebusan daunnya diminum sebagai obat rematik. Anas (Scaevola taccada) daunnya dipanaskan pada barah api kemudian dipakai untuk menekan ke bagian badan yang sakit seperti memar, keseleo ataupun pegalpegal, mares (Calophyllum inophylum) getah daunnya dicampur dengan air kemudian dipakai untuk mencuci muka sebagai obat sakit mata (mata merah), kris (terminalia cattapa) air rebusan kulit batangnya diminum sebagai obat malaria, wrar (Pongamia pinnata) air rebusan kulitnya diminum sebagai obat penyakit liver.

\section{d. Pemanfaatan Tumbuhan Mangrove sebagai Keperluan Lainnya}

Pemanfaatan tumbuhan mangrove untuk keperluan lainnya antara lain sebagai bahan pangan, pewarna, racun, dan alat tarsportasi. Bruguiera gymnorrhiza adalah jenis yang dimanfaatkan untuk bahan pangan dengan memanfaatkan patinya sebagai sumber karbohidrat. Sebagai racun digunakan buah rabon (Baringtonia asiatica), hasil parutan buah rabon dicampur dengan pakan umpan ikan digunakan sebagai racun ikan, sedangkan kulit batang jenis Rhizophora maupun Bruguiera dimanfaatkan oleh masyarakat sebagai bahan pewarna untuk jaring ikan terutama yang bahannya terbuat dari benang. Sedangkan pohon terminalia cattapa yang 
memiliki diameter batang lebih dari 100 dijadikan sebagai perahu yang digunakan untuk alat tarnsportasi antara kampung, juga digunakan oleh para nelayan untuk melaut di sekitar perairan kampung ababiaidi.

Berdasarkan hasil penelitian dapat disimpulkan bahwa pada lokasi penelitian ditemukan sebanyak 12 jenis tumbuhan mangrove dari 5 familia, keanekaragaman hayati tumbuhan mangrove pada lokasi penelitian tergolong sedang karena memiliki nilai indeks keanekaragaman $\left(\mathrm{H}^{\prime}\right)<3$, yaitu 2,25 dan pemanfaatan keanekaragaman tumbuhan mangrove antara lain sebagai bahan bangunan 9 jenis, sebagai sumber kayu bakar11 jenis, sebagai obat-obatan 3 jenis, dan 4 jenis untuk keperluan lainnya.

\section{DAFTAR PUSTAKA}

Bengen ,2002. Ekosistem dan Sumberdaya Alam Pesisir. Pusat Kajian Sumberdaya Pesisir dan Lautan. Sipnosis. Institut Pertanian Bogor. Bogor.

Dahuri, R., Rais, J., Ginting, S. P., Sitepu, M. J. 2004. Pengelolaan Sumber Daya Wilayah Pesisir dan Lautan Secara Terpadu. Cetakan III, Edisi Revisi 2004. Jakarta: Pradnya, Paramita.

Eduard, A. dan Husain,A. 2014. Tingkat Kerusakan Hutan Mangrove Pantai di Desa Malakosa Kecamatan Balinggi Kabupaten Parigi Moutong. Jurusan Kehutanan, Fakultas Kehutanan, Universitas Tadulako. Warta Rimba. ISSN: 2406-8373 Volume 2, Nomor 1.

Fachrul, M.F. 2007. Metode Sampling Bioekologi. Jakarta: Bumi Aksara

Frieldi dan Zulkifli 2012. Kelimpahan dan Nisbah Kelamin Siput Bakau (telescopium telescopium) di Ekosistem Mangrove Desa Darul Aman Kecamatan Rupat Kabupaten Bengkalis Fakultas Perikanan Universitas Riau. Jurnal Perikananan dan Kelautan issn 0853-7607

Kustanti,2011. Manajemen Hutan Mangrove.IPB Press.

Kordi K. 2012. Ekosistem Mangrove, potensi ,fungsi dan pengelolaan. Jakarta: Rineka Cipta.

Supriharyono,2007. Konservasi Ekosistem Sumber Daya Hayati di Wilayah Pesisir dan Laut Tropis. Yogyakarta: Pustaka Belajar.

Saparinto,C,2007. Pendayagunaan Ekosistem Mangrove. Semarang: Dahara Prize. 